\title{
Development and Field Application of a New Ultralow Guar Gum Concentration Weighted Fracturing Fluid in HPHT Reservoirs
}

\author{
Yi Liu (D), Jing Liu, Yunzi Li, Hui Yang, Fei Yan, Jiapeng Zheng, Jun Wu, Jianyi Huang, \\ Zuohao Wu, Cheng Luo, and Junkai Lu \\ Drilling and Production Technology Research Institute, Jidong Oilfield Company, PetroChina, Tangshan 063002, Hebei, China \\ Correspondence should be addressed to Yi Liu; liu0yi@163.com
}

Received 30 March 2020; Revised 3 August 2020; Accepted 25 August 2020; Published 12 November 2020

Academic Editor: James Barker

Copyright (c) 2020 Yi Liu et al. This is an open access article distributed under the Creative Commons Attribution License, which permits unrestricted use, distribution, and reproduction in any medium, provided the original work is properly cited.

\begin{abstract}
A weighted fracturing fluid with superlow guar gum concentration was developed by synthesizing a polyboric acid cross-linker. The density of this fluid is $1.365 \mathrm{~g} / \mathrm{cm}^{3}$ and can withstand very high temperature up to $175^{\circ} \mathrm{C}$. In this study, a weighting agent was selected, and crosslinking ligands and boric acid were optimized. The crosslinking performance, base fluid viscosity, rheology, and gel-breaking performance of this fracturing fluid were studied. Compared with the conventional weighted fracturing fluid, the concentration of guar gum in the new weighted fracturing fluid can be reduced by $30 \%$ at the same temperature condition; moreover, crosslinking can be delayed by 2 minutes. The concentration of gel breaker used in this fluid can be significantly reduced to $0.005 \% \sim 0.01 \%$. Two field tests were conducted in Jidong oil field, and both of them achieved great success.
\end{abstract}

\section{Introduction}

Weighted fracturing fluid (also called high-density fracturing fluid) has become more and more important for fracturing of high-temperature and high-pressure reservoirs (especially over $160^{\circ} \mathrm{C}$ ). Adding weighted materials into the fracturing fluid is an effective way to increase fluid density and thus reduce wellhead pressure. For example, for a $5000 \mathrm{~m}$ well, every $0.1 \mathrm{~g} / \mathrm{cm}^{3}$ increase in fracturing fluid density will contribute to a $5 \mathrm{MPa}$ wellhead pressure decrease [1-5].

However, a major challenge is that the fluid performance might change a lot with the addition of weighting agents. Adding a large amount of weighting agents into the solution will result in inhomogeneity and long thickening time, which will lead to poor temperature and shear resistance. Viscoelastic surfactant is a good choice for the high-density fracturing fluid due to its good salt resistance, but its poor temperature resistance (below $120^{\circ} \mathrm{C}$ ) and expensive cost of the raw material have prevented its use in the oilfield. Guar gum and hydroxypropyl guar gum cost much less than the viscoelastic surfactant and can mitigate the solubility problem of thickeners in saline solution, together with the organic baron crosslinking agent, which has excellent shear recovery, and can delay crosslinking. Therefore, the combination of hydroxypropyl guar gum and organic boron cross-linker is believed to be an ideal weighted fracturing fluid [6].

The temperature resistance of the fracturing fluid is highly demanded for high-temperature reservoirs (above $160^{\circ} \mathrm{C}$ ). A large amount of guar gum and temperature stabilizers are needed to meet the temperature and shear resistance of the high-temperature fracturing fluid [7]. Besides, as temperature varies with seasons, plus the dissolution and endothermic of sodium nitrate and other salts may absorb heat, the temperature of the weighted fracturing fluid often decreases (especially in winter), which will lead to an increase in apparent viscosity of the base fluid. Furthermore, high-apparent viscosity base fluid will affect fluid supply and increase pipe friction during fracturing process. The addition of the temperature stabilizer will also increase the concentration of the gel breaker in the fluid system. In addition, collected field data revealed that the gel-breaking property of the existing high-density fracturing fluid is poor, 
and the concentration of the gel breaker is relatively high (0.05-0.1\%), which affects gel flowback rate after fracturing treatment $[8-10]$.

In order to overcome these difficulties, we optimized the boric acid source and crosslinking ligand grade, added ester bonds to the molecular structure, and increased the usage of boric acid to improve the rigidity and flexibility of the coordination bond. As a result, a polyboric acid crosslinking agent was synthesized, and a weighted fracturing fluid with superlow guar gum concentration was formed in this study. Two field tests were conducted in Jidong oil field, and both of them achieved great success.

\section{Materials and Methods}

2.1. Experimental Materials. Sodium gluconate 1 $\left(\mathrm{CH}_{2} \mathrm{OH}(\mathrm{CHOH})_{4} \mathrm{COONa}\right.$, industrial grade), sodium gluconate $2\left(\mathrm{CH}_{2} \mathrm{OH}(\mathrm{CHOH})_{4} \mathrm{COONa}\right.$, food grade $)$, boric acid $1\left(\mathrm{~B}(\mathrm{OH})_{3}\right.$, industrial grade, Russia), boric acid $2\left(\mathrm{~B}(\mathrm{OH})_{3}\right.$, industrial grade, China), hydroxypropyl guar gum (HPG, industrial grade), sodium nitrate $\mathrm{A}\left(\mathrm{NaNO}_{3}\right.$, industrial grade), and sodium nitrate $\mathrm{B}\left(\mathrm{NaNO}_{3}\right.$, industrial grade) were used.

Sodium hydroxide $(\mathrm{NaOH})$, glycerol $\left(\mathrm{CH}_{2} \mathrm{OHCHOH}-\right.$ $\left.\mathrm{CH}_{2} \mathrm{OH}\right)$, potassium chloride $(\mathrm{KCl})$, ammonium persulfate $\left(\left(\mathrm{NH}_{4}\right)_{2} \mathrm{~S}_{2} \mathrm{O}_{8}\right)$, and sodium carbonate $\left(\mathrm{Na}_{2} \mathrm{CO}_{3}\right)$ were purchased from Sichuan Kelong Chemical Reagent Factory. All the chemicals used were of analytical grade, and no purification was required before experiments. JDY-1 (polyboric acid cross-linker) was self-made in the laboratory, and ZCY10 (conventional organic boron cross-linker) was purchased from Bohai Drilling Engineering Technology Institute).

\subsection{Experimental Instruments. WT-VSA-2000B Warring} Mixer, offered by the Beijing Institute of Mineral Exploration Engineering, was used to configure the base fluid of the fracturing fluid. RS6000 Rheometer, provided by Thermo Fisher Scientific, was used to test the temperature and shear resistance of the fracturing fluid. Fourier-transform infrared spectrometer (Nicolet 6700), provided by Thermo Fisher Scientific, was used to analyze the functional groups of the sample. EDS (EDAX Genesis), provided by EDAX (USA), was used to analyze the elements of the sample and the mass fraction of each element.

\subsection{Experimental Methods and Principles}

2.3.1. Preparation of Polyboric Acid Cross-Linker. The solution was prepared by dissolving $13 \mathrm{~g}$ glycerin in $39 \mathrm{~g}$ distilled water under magnetic stirring. Then, $25 \mathrm{~g}$ boric acid 1 (Russia) was slowly added into the solution under constant stirring at room temperature. After that, $16 \mathrm{~g}$ sodium gluconate (food grade) and $7 \mathrm{~g}$ ester organic ligand 2 were added, and the mixture was slowly stirred for 3 hours at $60-70^{\circ} \mathrm{C}$. Then, sodium hydroxide was added to adjust the solution $\mathrm{pH}$ value to 7 . After that, the final polyboric acid cross-linker (JDY-1) was obtained.
2.3.2. Characterization of JDY-1. 1 2 mg dried JDY-1 were grinded into powder in an agate mortar and then mixed evenly with $100 \mathrm{mg}$ dried potassium bromide (KBr, AR class) powder. The FTIR spectra of the sample were measured using a Fourier-transform infrared spectrometer (Nicolet 6700) provided by Thermo Fisher Scientific. Elementary analysis of cross-linkers was investigated by EDS.

2.3.3. Performance Evaluation of the Weighted Fracturing Fluid. The apparent viscosity of the base fracturing fluid was tested using six-speed viscometer at $25^{\circ} \mathrm{C}$ with a shearing rate of $170 \mathrm{~S}^{-1}$. Temperature and shearing resistance of gel were measured via RS6000 Rheometer provided by Thermo Fisher Scientific (Germany) at different temperatures and sheared at $170 \mathrm{~S}^{-1}$. Gel-breaking performance was tested at different concentrations of ammonium persulfate $\left(\left(\mathrm{NH}_{4}\right)_{2} \mathrm{~S}_{2} \mathrm{O}_{8}\right)$ at different temperatures.

\section{Results and Discussion}

\subsection{Synthesis and Characterization of JDY-1}

3.1.1. Optimization of Crosslinking Ligands. The first procedure of synthesis of polyboric acid cross-linker is to select a suitable crosslinking ligand. In this study, industrial-grade sodium gluconate 1 and food-grade sodium gluconate 2 were evaluated as crosslinking ligands of the fracturing fluid. As shown in Figure 1, the apparent viscosity of the fracturing fluid using sodium gluconate 2 (food grade) is higher than that of sodium gluconate 1 (industrial grade). The result confirmed food-grade sodium gluconate 2 had better temperature and shear resistance than industrial-grade sodium gluconate 1 . This is due to the extremely high purity and low concentration of heavy metal ions of food-grade sodium gluconate. Therefore, the fracturing fluid using food-grade sodium gluconate 2 as a crosslinking ligand has better temperature and shear resistance.

The characteristics of sodium gluconate 2 and crosslinking ligand 2 were also evaluated. The test was conducted at $150^{\circ} \mathrm{C}$ and sheared at $170 \mathrm{~s}^{-1}$. The apparent viscosity of gels formed by sodium gluconate was higher than that of crosslinking ligand 2, indicating that the temperature resistance of sodium gluconate 2 was better than that of crosslinking ligand 2 at $150^{\circ} \mathrm{C}$.

As a crosslinking ligand, sodium gluconate has strong temperature resistance and can improve rigidity of crosslinking bonds. The temperature resistance of gel can be improved by increasing the concentration of boric acid in a certain range; once it exceeds the range, gel dehydration phenomenon occurs. The gel would become brittle and lose part of its shear resistance. However, when using the combination of ester crosslinking ligand 2 and sodium gluconate, dehydration phenomenon did not occur with the increase of boric acid concentration (Table 1). This is due to the reversible esterification reaction which provided more crosslinking points, which improved the flexibility of crosslinking bonds, and thus increased the probability of recrosslinking under dynamic conditions. 


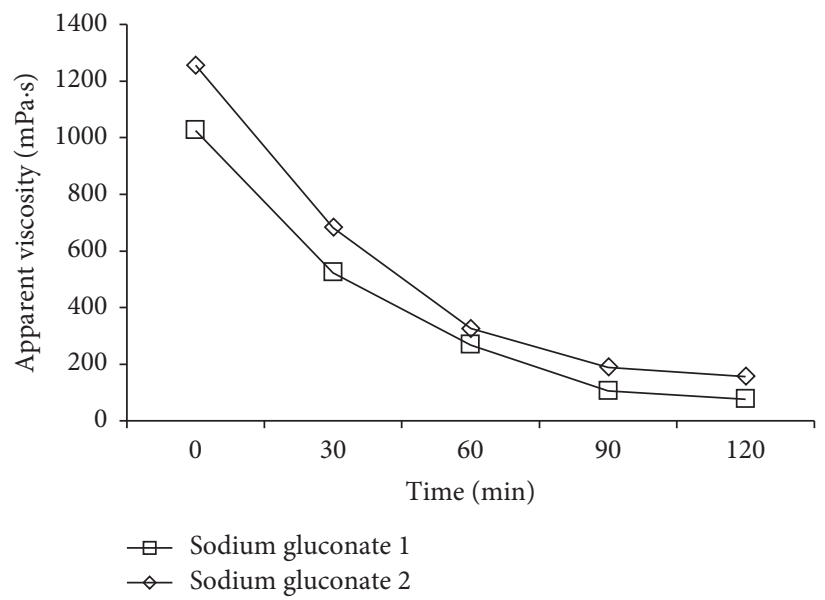

FIGURE 1: Apparent viscosity of the fracturing fluid using sodium gluconate 1 and sodium gluconate 2.

TABLE 1: Characteristics of the conventional density fracturing fluid using different crosslinking ligands.

\begin{tabular}{lcccc}
\hline Sodium gluconate 2\% & Ligand 2\% & Boric acid 2\% & Crosslinked gel & Apparent viscosity $\left(150^{\circ} \mathrm{C}, 1 \mathrm{~h}\right)$ \\
\hline 15 & & 15 & Low-viscosity gel & Quickly decreased \\
20 & & 15 & Good crosslinked gel & Quickly decreased \\
25 & & Good crosslinked gel & $36 \mathrm{cp}$ \\
25 & & Gel is brittle and dehydrated & $65 \mathrm{cp}$ \\
25 & 15 & Gel is brittle and dehydrated & $130 \mathrm{cp}$ \\
& 20 & 25 & Low-viscosity gel & Quickly decreased \\
& 20 & 20 & Good crosslinked gel & Quickly decreased \\
& 25 & 20 & Good crosslinked gel & $33 \mathrm{cp}$ \\
16 & 25 & 22 & Good crosslinked gel without dehydration & $52 \mathrm{cp}$ \\
16 & 25 & 25 & Good crosslinked gel without dehydration & $266 \mathrm{cp}$ \\
\hline
\end{tabular}

As a result, the combination of food-grade sodium gluconate $2(16 \mathrm{wt} \%)$ and ester crosslinking ligand 2 (7 wt $\%)$ was determined to be the optimal result of the new crosslinking ligands. The apparent viscosity of gel reached $381 \mathrm{mPa} \cdot \mathrm{s}$ after 1 hour at $150^{\circ} \mathrm{C}$.

3.1.2. Optimization of Boric Acid. The apparent viscosity of conventional density fracturing fluids (density $1.0 \mathrm{~g} / \mathrm{cm}^{3}$ ) using boric acid 1 (Russia) and boric acid 2 (China) was evaluated. Crosslinked gel 1 was formed with $16 \%$ sodium gluconate 2, 7\% ligand 2, and a certain amount of boric acid 1 (Russia). Crosslinked gel 2 was formed with $16 \%$ sodium gluconate 2, 7\% ligand 2, and a certain amount of boric acid 2 (China).

As shown in Table 2, experimental results indicated that, after 1 hour of shearing, the apparent viscosity of gel $2(189 \sim 381 \mathrm{mPa} \cdot \mathrm{s})$ was lower than that of gel 1 (215 408 $\mathrm{mPa} \cdot \mathrm{s})$, which means the temperature resistance of gel 1 was better. This is mainly due to the difference in processing procedures and technology, as well as the quality of raw materials of boric acids. Therefore, the formula of $16 \%$ sodium gluconate $2,7 \%$ crosslinking ligand 2 , and $25 \%$ boric acid 1 was determined to be the optimum formula.
3.1.3. Characterization of the Crosslinking Agent. The structure of the cross-linker was measured using a Fouriertransform infrared spectrometer (Nicolet 6700).

The structure of the cross-linker was confirmed by FTIR as illustrated in Figure 2. The strong absorption peak appeared at $3446.45 \mathrm{~cm}^{-1}$ generated by the stretching vibration of the $\mathrm{O}-\mathrm{H}$ bond. The second absorption peak appeared at $2889.71 \mathrm{~cm}^{-1}$ caused by the stretching vibration of the $\mathrm{C}-\mathrm{H}$ bond. The third absorption peak at $1732.74 \mathrm{~cm}^{-1}$ indicates the stretching vibration of the $\mathrm{C}=\mathrm{O}$ bond. The broad and strong absorption peak at $1080.76 \mathrm{~cm}^{-1}$ is the symmetric stretching vibration of C-O-C bonds; absorption peaks at $950.27 \mathrm{~cm}^{-1}$ and $1361.98 \mathrm{~cm}^{-1}$ are the characteristic absorption of the stretching vibration of the B-O bond, indicating the synthesized product contains $\mathrm{B}-\mathrm{O}-\mathrm{H}$ and C-O-C groups. As expected, the FTIR spectrum confirmed the presence of different groups in JDY-1.

Elementary analysis of cross-linkers was investigated by EDS as illustrated in Table 3. As expected, both cross-linkers contained carbon $(\mathrm{C})$, oxygen $(\mathrm{O})$, boron $(\mathrm{B})$, and sodium $(\mathrm{Na})$. Due to equipment limitations, hydrogen cannot be recognized. The $\mathrm{O} / \mathrm{C}$ molar ratio of sodium gluconate was $1.39: 1$, while the $\mathrm{O} / \mathrm{C}$ molar ratio was $1.52: 1$ in JDY-1. The proportion of carbon $(\mathrm{C})$ and oxygen $(\mathrm{O})$ both increased in JDY-1. This may be because JDY-1 consisted of the ester 
TABLE 2: Experiment results of conventional density fracturing fluids using different boric acid.

\begin{tabular}{lcccccc}
\hline Sample & $\begin{array}{c}\text { Sodium } \\
\text { gluconate } 2 \%\end{array}$ & $\begin{array}{c}\text { Ligand } \\
2 \%\end{array}$ & $\begin{array}{c}\text { Boric acid } \\
1 \%\end{array}$ & $\begin{array}{c}\text { Boric acid } \\
2 \%\end{array}$ & Crosslinked gel & $\begin{array}{c}\text { Apparent viscosity }\left(150^{\circ} \mathrm{C},\right. \\
1 \mathrm{~h})\end{array}$ \\
\hline \multirow{3}{*}{ Crosslinkedgel 1 } & 16 & 7 & 15 & & & 215 \\
& 16 & 7 & 18 & & & 232 \\
& 16 & 7 & 20 & & Good crosslinked gel without & 408 \\
Crosslinked gel 2 & 16 & 7 & 25 & & dehydration & 289 \\
& 16 & 7 & & 15 & & 201 \\
& 16 & 7 & & 18 & & 381 \\
\end{tabular}

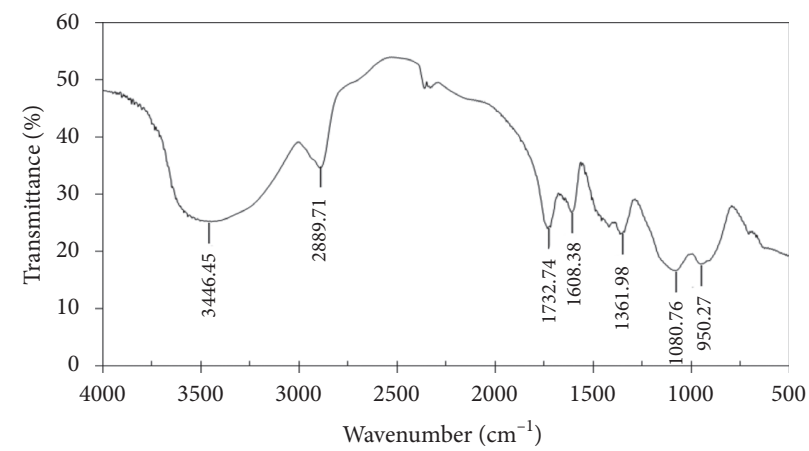

FIGURE 2: Infrared spectrogram of the crosslinking agent.

TABLE 3: Elementary analysis test results of cross-linkers.

\begin{tabular}{lcc}
\hline \multirow{2}{*}{ Element } & $\begin{array}{c}\text { Sodium gluconate } \\
\text { At\% }\end{array}$ & $\begin{array}{c}\text { JDY-1 } \\
\text { At } \%\end{array}$ \\
\hline $\mathrm{C}$ & 22.4 & 26.04 \\
$\mathrm{O}$ & 31.2 & 39.6 \\
$\mathrm{~B}$ & 26.3 & 25.6 \\
$\mathrm{Na}$ & 19.9 & 8.53 \\
\hline
\end{tabular}

crosslinking ligand and sodium gluconate, and the ester crosslinking ligand has more carbon atoms than sodium gluconate $\left(\mathrm{C}_{6} \mathrm{H}_{11} \mathrm{O}_{7} \mathrm{Na}\right)$. As expected, the results confirmed the element composition of JDY-1.

\subsection{Optimization and Evaluation of the Weighted Fracturing Fluid}

3.2.1. Optimization of the Weighting Agent. In this study, sodium nitrate provided by two manufacturers (A and B) was selected for lab experiments. The fluid samples were prepared by using weighting agents $\mathrm{A}$ and $\mathrm{B}$. The densities and crosslinking abilities of samples A and B were studied. The experiment results demonstrate that there is no obvious difference in fluid densities. However, when sodium carbonate $\left(\mathrm{Na}_{2} \mathrm{CO}_{3}\right)$ was added to fluid sample $\mathrm{A}$, crosslinking phenomenon occurred immediately, while no significant change in fluid sample $B$. This might be explained that industrial-grade sodium nitrate generally contains $\mathrm{Fe}^{3+}$ (the concentration of $\mathrm{Fe}^{3+}$ less than $0.005 \mathrm{wt} \%$ ), which will crosslink with guar gum. Sodium nitrate B may be of higher standard and did not contain $\mathrm{Fe}^{3+}$, so crosslinking was not observed in sample B. As a result, weighting agent B was selected.

3.2.2. Viscosity Test of the Base Fluid. The objective of this test is to measure apparent viscosity at different conditions when weighting agent B was added to the solution. Table 4 shows the apparent viscosity of the weighted fracturing fluid is always greater than that of the conventional density fracturing fluid (density $1.0 \mathrm{~g} / \mathrm{cm}^{3}$ ). Moreover, the apparent viscosity of the conventional density base fluid did not change with ambient temperature, while the apparent viscosity of the weighted fracturing base fluid increased significantly with ambient temperature decreased. For example, at $25^{\circ} \mathrm{C}$, when guar gum concentration was $0.5 \mathrm{wt} \%$, the corresponding apparent viscosity of the conventional density base fluid (density $1.0 \mathrm{~g} / \mathrm{cm}^{3}$ ) was $72 \mathrm{mPa} \cdot \mathrm{s}$; however, at the same condition $\left(25^{\circ} \mathrm{C}\right.$, concentration $\left.0.5 \mathrm{wt} \%\right)$, the corresponding apparent viscosity of the weighted base fluid (density $1.32 \mathrm{~g} / \mathrm{cm}^{3}$ ) increased to $96 \mathrm{mPa} \cdot \mathrm{s}$. When the temperature falls to $15^{\circ} \mathrm{C}$, the corresponding apparent viscosity of the weighted base fluid (density $1.32 \mathrm{~g} / \mathrm{cm}^{3}$ ) would increase to $114 \mathrm{mPa} \cdot \mathrm{s}$ (guar gum concentration $0.5 \mathrm{wt} \%$ ) (Table 4).

The reasons can be explained as follows: the salt proportion in the weighted fracturing fluid was high, so the actual amount of water contributing to the fluid was relatively low, which would increase the apparent viscosity of the weighted fracturing fluid. In addition, due to the influence of melting and heat absorption of sodium nitrate and other salts, the temperature of the fracturing fluid often decreased, 
TABLE 4: Base fluid viscosity of different density fracturing fluids under different guar gum concentrations.

\begin{tabular}{|c|c|c|c|c|c|}
\hline Fracturing fluid & $\begin{array}{l}\text { Temperature } \\
\left({ }^{\circ} \mathrm{C}\right)\end{array}$ & $\begin{array}{l}\text { Concentration } \\
\text { of } \\
\text { guar gum }(\%)\end{array}$ & $\begin{array}{l}\text { Density } \\
\left(\mathrm{g} / \mathrm{cm}^{3}\right)\end{array}$ & $\begin{array}{c}\text { Apparent viscosit } \\
\text { y of the base fluid } \\
\text { at } 170 \mathrm{~s}^{-1} \text { shear rate } \\
(\mathrm{mPa} \cdot \mathrm{s})\end{array}$ & $\begin{array}{l}\text { Weighting } \\
\text { agent }\end{array}$ \\
\hline $\begin{array}{l}\text { Base fluid of hydroxypropyl guar gum fracturing } \\
\text { fluid }\end{array}$ & $\begin{array}{l}\text { Ambient } \\
\text { temperature }\end{array}$ & $\begin{array}{c}0.45 \\
0.5 \\
0.55\end{array}$ & 1.0 & $\begin{array}{l}69 \\
72 \\
86\end{array}$ & None \\
\hline $\begin{array}{l}\text { Base fluid of weighted hydroxypropyl guar gum } \\
\text { fracturing fluid }\end{array}$ & $\begin{array}{l}25^{\circ} \mathrm{C} \\
15^{\circ} \mathrm{C}\end{array}$ & $\begin{array}{c}0.45 \\
0.5 \\
0.55 \\
0.45 \\
0.5 \\
0.55\end{array}$ & 1.32 & $\begin{array}{c}72 \\
96 \\
105 \\
87 \\
114 \\
123\end{array}$ & $\begin{array}{l}\text { Sodium nitrate } \\
\text { B }\end{array}$ \\
\hline
\end{tabular}

which leaded to an increasing viscosity of the base fluid. Furthermore, since the temperatures of reservoirs can be as high as $160^{\circ} \mathrm{C}$ or even above, the amount of thickener added to the fracturing fluid was relatively high in order to ensure the temperature resistance of the gel.

From field experience in Jidong oil field, the apparent viscosity of the base fluid exceeding $90 \mathrm{mPa} \cdot \mathrm{s}$ will increase pipe friction and limit the flow rate, which will affect pumping process and cause serious troubles during operation. Therefore, $0.45 \mathrm{wt} \%$ was determined to be the upper limit of guar gum concentration to make sure the apparent viscosity of the base fluid remained under $90 \mathrm{mPa} \cdot \mathrm{s}$.

3.2.3. Optimization of the Cross-Linker. Two kinds of borate cross-linkers, JDY-1 (polyboric acid cross-linker) and ZCY10 (conventional organic boron cross-linker), were evaluated in this study. Besides, high temperature shear tests were carried out at $160^{\circ} \mathrm{C}$ and sheared at $170 \mathrm{~s}^{-1}$.

Figure 3 indicates JDY-1 and ZCY-1 have a big difference in temperature resistance when sheared at $170 \mathrm{~s}^{-1}$ under the same guar gum concentration and density. At $160^{\circ} \mathrm{C}$, JDY-1, with $0.4 \%$ guar gum concentration, can withstand 120 minutes of shearing and ended up with a $60 \mathrm{mPa} \cdot \mathrm{s}$ apparent viscosity, while ZCY-10, with $0.5 \%$ guar gum concentration, can only withstand 40 minutes of shearing and ended up with a $40 \mathrm{mPa} \cdot \mathrm{s}$ apparent viscosity. As a result, JDY-1 performed better and was determined to be the final crosslinker of the fluid system.

\subsection{Performance Evaluation of the Weighted Fracturing Fluid}

3.3.1. Crosslinking Performance. The crosslinking tests of fracturing fluids with different densities were carried out. For conventional fracturing fluids (density $1.0 \mathrm{~g} / \mathrm{cm}^{3}$ ), crosslinking is not a problem. However, the crosslinking performance of the weighted fracturing fluid may be affected by the concentration of the cross-linker and regulator. The experiment results confirmed that increasing cross-linker concentration would improve the crosslinking performance. Table 5 indicates for conventional fracturing fluids (density $1.0 \mathrm{~g} / \mathrm{cm}^{3}$ ), crosslinking gels were good and stable, and crosslinking time was acceptable. As fluid density increased, the crosslinking of the fracturing fluid costs more time, and the crosslinking performance was weakened, indicating the addition of sodium nitrate affected the crosslinking performance. However, the crosslinked gel can be improved significantly, and the crosslinking time can also be shortened by increasing the dosage of the cross-linker.

3.3.2. Rheology. Three different fracturing fluid samples were prepared based on the following formulas:

Formula 1: $0.4 \% \mathrm{HPG}+0.4 \%$ regulator $+0.5 \% \mathrm{JDY}-$ $1+0.12 \% \quad \mathrm{Na}_{2} \mathrm{CO}_{3}+0.3 \%$ cleanup additive $+0.5 \%$ antiswelling agent $+1 \% \mathrm{KCl}+40 \%$ sodium nitrate $\mathrm{B}$.

Formula 2: $\quad 0.45 \% \quad \mathrm{HPG}+0.5 \%$ regulator $+0.15 \%$ $\mathrm{Na}_{2} \mathrm{CO}_{3}+0.3 \%$ cleanup additive $+0.5 \%$ antiswelling agent $+1 \% \quad \mathrm{KCl}+0.6 \% \quad$ JDY $-1+0.1 \%$ temperature stabilizer $+40 \%$ sodium nitrate $\mathrm{B}$.

Formula 3: $\quad 0.45 \% \quad \mathrm{HPG}+0.7 \%$ regulator $+0.15 \%$ $\mathrm{Na}_{2} \mathrm{CO}_{3}+0.3 \%$ cleanup additive $+0.5 \%$ antiswelling agent $+1 \% \quad \mathrm{KCl}+0.7 \% \quad \mathrm{ZCY}-10+0.3 \%$ temperature stabilizer $+40 \%$ sodium nitrate $\mathrm{B}$.

JDY-1 was used as a cross-linker in formulas 1 and 2, while ZCY-10 in formula 3. The tests were conducted at different temperature conditions. The rheology characteristics of these samples were studied. Detailed descriptions and figures were given.

Figures 4 and 5 compare the temperature and shear resistance of the weighted fracturing fluid and conventional $\left(1.0 \mathrm{~g} / \mathrm{cm}^{3}\right)$ fracturing fluid. Figure 4 shows that the weighted fracturing fluid could withstand very high temperature (up to $160^{\circ} \mathrm{C}$ ), while the conventional fracturing fluid can only withstand $130^{\circ} \mathrm{C}$. That is to say, compared with the conventional density fracturing fluid, the temperature and shear 


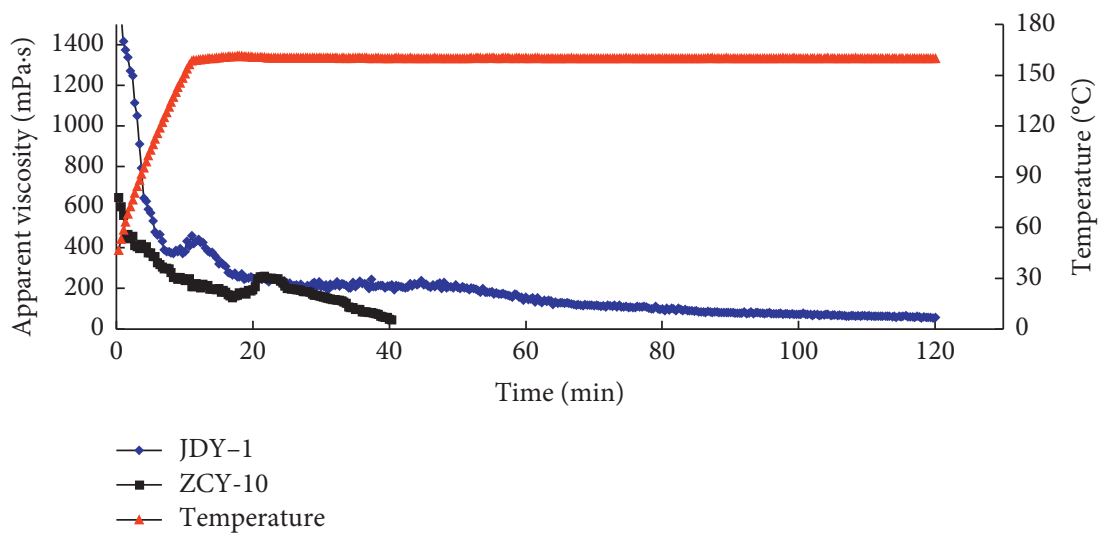

FIgURE 3: Temperature and shear resistance of the high-density fracturing fluid at $160^{\circ} \mathrm{C}$ and $170 \mathrm{~s}^{-1}$.

TABle 5: Crosslinking performance of fracturing fluids with different densities.

\begin{tabular}{lcccc}
\hline Cross-linker (\%) & Density $\left(\mathrm{g} / \mathrm{cm}^{3}\right)$ & Regulator $(\%)$ & Crosslinking time (min) & Crosslinking gel \\
\hline 0.55 & 1.3 & 0.4 & 1 min $50 \mathrm{~s}$ & Well \\
0.5 & 1.3 & 0.4 & 2 min $40 \mathrm{~s}$ & Well \\
0.45 & 1.3 & 0.4 & - & Bad cross-linked \\
0.4 & 1.3 & 0.3 & 1 min & Bad cross-linked \\
0.5 & 1.0 & 0.4 & 1 min $30 \mathrm{~s}$ & Well \\
0.45 & 1.0 & 0.4 & 2 min & Well \\
0.4 & 1.0 & 0.4 & & Well \\
\hline
\end{tabular}

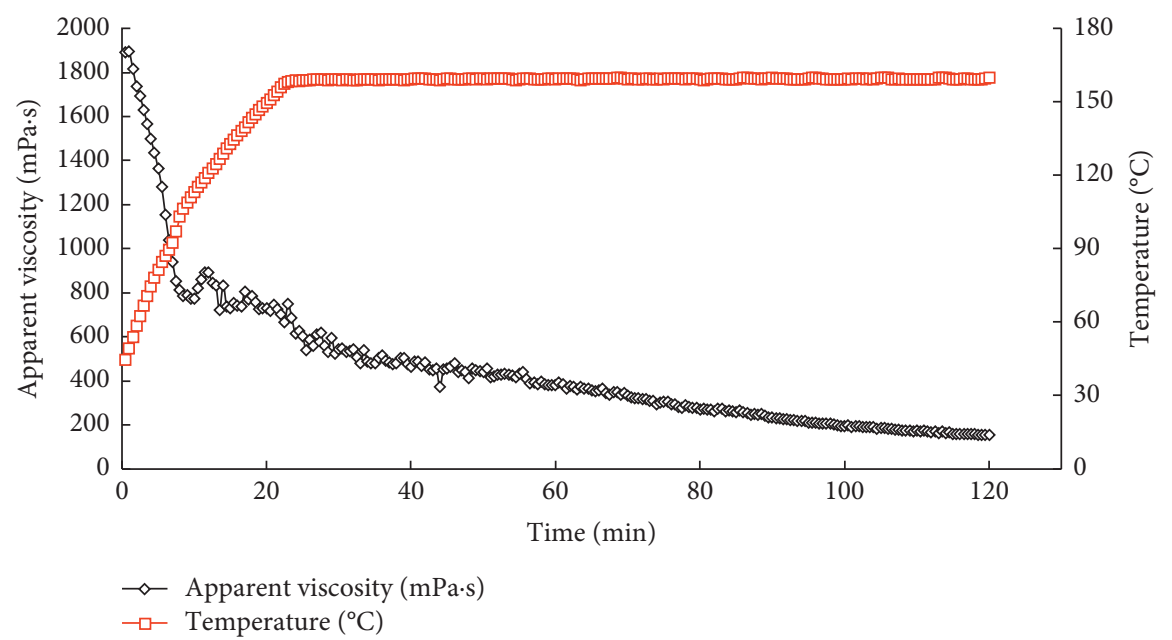

FIGURE 4: Temperature and shear resistance of the high-density fracturing fluid of formula 1.

resistance of the weighted fracturing fluid improved significantly.

Figures 6 and 5 demonstrate the temperature and shear resistance of both high-density and conventional density fracturing fluids using formula 2. Figure 6 indicates the highdensity fluid system can withstand very high temperature up to $175^{\circ} \mathrm{C}$. The apparent viscosity was $68 \mathrm{mPa} \cdot \mathrm{s}$ after 90 minutes at $175^{\circ} \mathrm{C}$. Figure 7 compares the apparent viscosity of the conventional fluid system at $140^{\circ} \mathrm{C}$ and $150^{\circ} \mathrm{C}$. It is obvious that the conventional fracturing fluid using formula 2 can withstand $140^{\circ} \mathrm{C}$, but cannot withstand $150^{\circ} \mathrm{C}$. At $140^{\circ} \mathrm{C}$, the apparent viscosity of the conventional density fluid using formula 2 was $104 \mathrm{mPa} \cdot \mathrm{s}$ after 120 minutes of shearing, while at $150^{\circ} \mathrm{C}$, the apparent viscosity was only $44 \mathrm{mPa} \cdot \mathrm{s}$ after 120 minutes of shearing.

Figure 8 shows the temperature and shear resistance of the formula 3 fluid system. Formula 3 used $0.3 \%$ temperature stabilizer, $0.45 \%$ HPG concentration, and ZCY-10 as the cross-linker. The fluid system can only resist up to $150^{\circ} \mathrm{C}$. Since $0.45 \%$ was determined as the upper limit of guar concentration in Section 3.2.2, formula 2 was determined as the optimal formula at $175^{\circ} \mathrm{C}$. The results also confirmed 


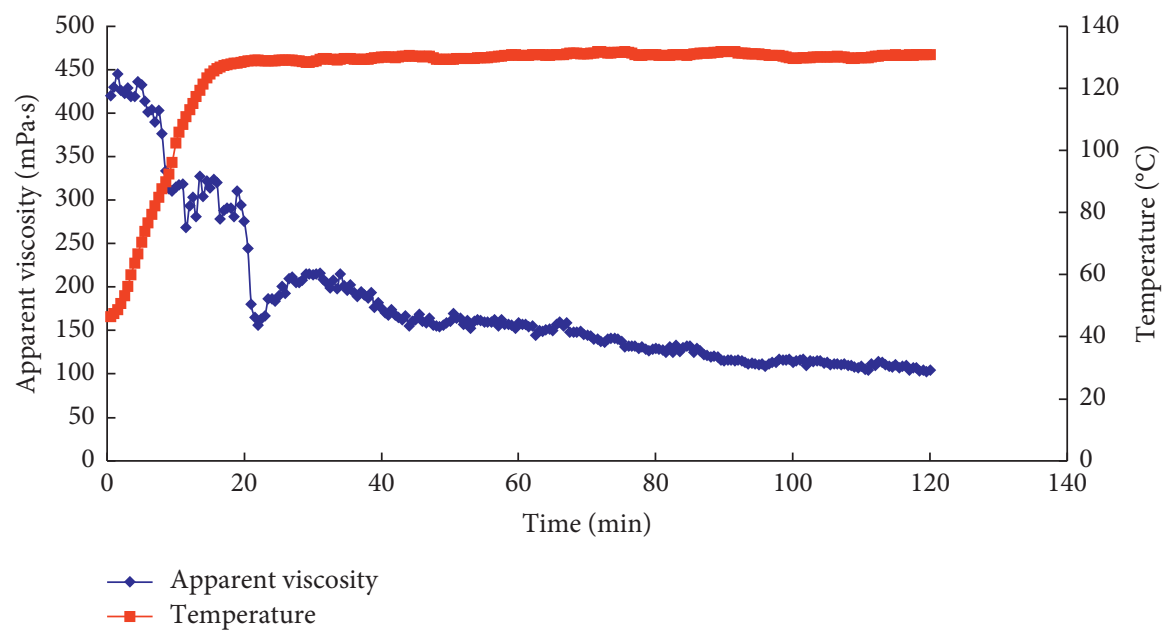

FIGURE 5: Temperature and shear resistance of the conventional density fracturing fluid of formula 1.

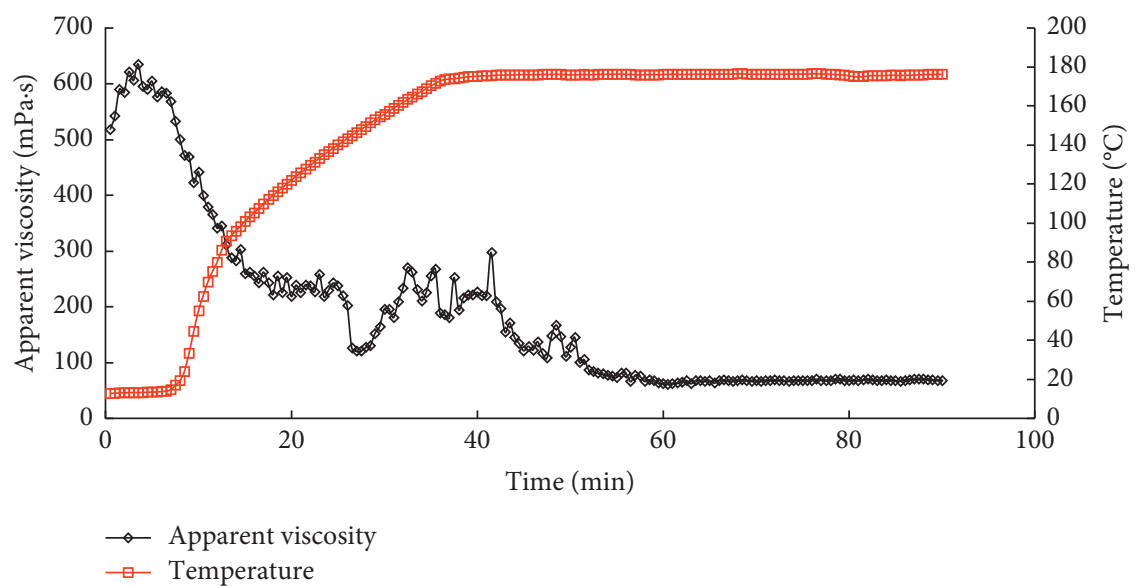

Figure 6: Temperature and shear resistance of the high-density fracturing fluid of formula 2.

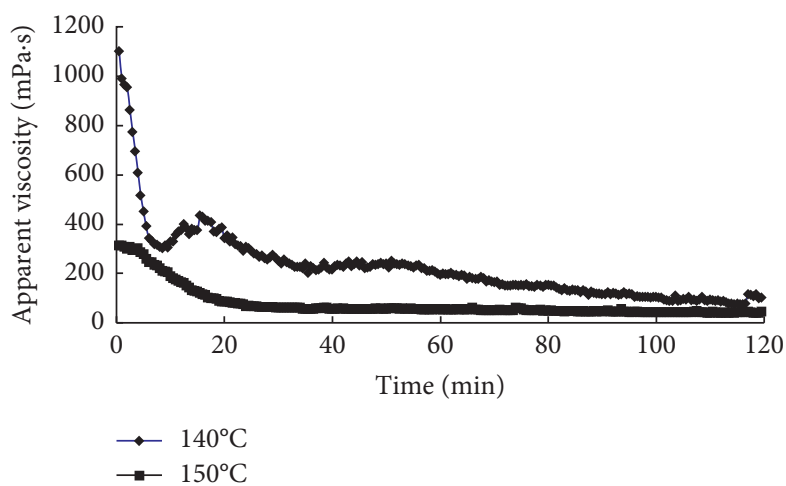

Figure 7: Temperature and shear resistance of the conventional density fracturing fluid of formula 2.

JDY-1 had excellent temperature resistance. Furthermore, it can effectively reduce guar gum concentration and overcome the difficulties that the high-apparent viscosity base fluid may cause, such as fluid supply and pipe friction issues.
3.3.3. Gel Breaking. The gel-breaking properties of the weighted fracturing fluid using JDY-1 and ZCY-10 were studied. Tables 6 and 7 demonstrate the gel-breaker profiles at $120^{\circ} \mathrm{C}$ and $140^{\circ} \mathrm{C}$. At $120^{\circ} \mathrm{C}$, JDY-1 gel has good performance. 


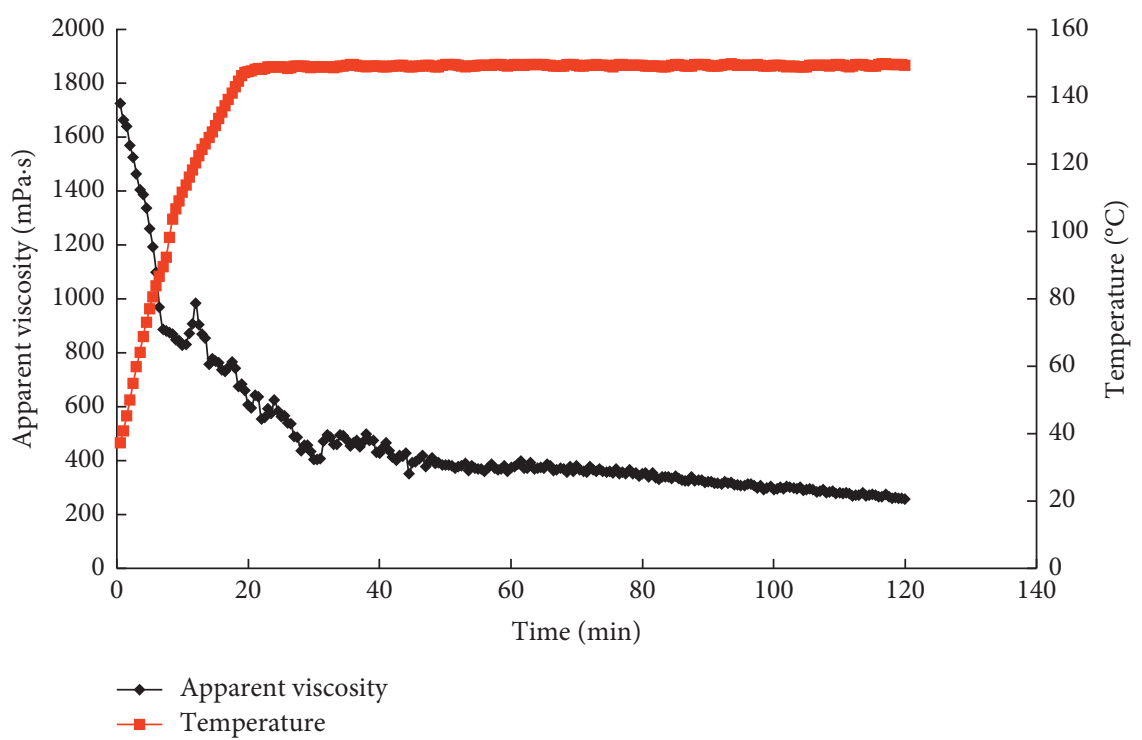

Figure 8: Temperature and shear resistance of the high-density fracturing fluid of formula 3 at $150^{\circ} \mathrm{C}$.

TABLe 6: Gel-breaker profile of the weighted fracturing fluid at $120^{\circ} \mathrm{C}$.

\begin{tabular}{|c|c|c|c|c|c|c|}
\hline \multirow{2}{*}{ Cross-linker } & \multirow{2}{*}{ Gel-breaking time $(\mathrm{h})$} & \multicolumn{5}{|c|}{ Concentration of ammonium persulfate (wt\%) } \\
\hline & & 0.005 & 0.01 & 0.02 & 0.03 & 0.05 \\
\hline \multirow{3}{*}{$Z C Y-10$} & 2 & Not break & Not break & Not break & Not break & Not break \\
\hline & 8 & Not break & Not break & Not break & Not break & Not break \\
\hline & 12 & Not break & Not break & Not break & Not break & Not break \\
\hline \multirow{2}{*}{$J D Y-1$} & 1 & Thin & Thin & Thin & Thin & $\leq 5 \mathrm{mPa} \cdot \mathrm{s}$ \\
\hline & 2 & $\leq 5 \mathrm{mPa} \cdot \mathrm{s}$ & $\leq 5 \mathrm{mPa} \cdot \mathrm{s}$ & $\leq 5 \mathrm{mPa} \cdot \mathrm{s}$ & $\leq 5 \mathrm{mPa} \cdot \mathrm{s}$ & $\leq 5 \mathrm{mPa} \cdot \mathrm{s}$ \\
\hline
\end{tabular}

TABLe 7: Gel-breaker profile of the weighted fracturing fluid at $140^{\circ} \mathrm{C}$.

\begin{tabular}{ccccccc}
\hline \multirow{2}{*}{ Cross-linker } & \multirow{2}{*}{ Gel-breaking time $(\mathrm{h})$} & \multicolumn{4}{c}{ Concentration of ammonium persulfate (wt\%) } \\
& & 0.005 & 0.01 & 0.02 & 0.05 & 0.1 \\
\hline \multirow{2}{*}{$Z C Y-10$} & 2 & Not break & Not break & Not break & Not break & Not break \\
& 8 & Not break & Not break & Not break & Thin & Gel appeared again \\
& 12 & Not break & Not break & Thin & Gel appeared again & Gel appeared again \\
\hline \multirow{2}{*}{$J D Y-1$} & 1 & Thin & Thin & $\leq 5 \mathrm{mPa} \cdot \mathrm{s}$ & $\leq 5 \mathrm{mPa} \cdot \mathrm{s}$ & $\leq 5 \mathrm{mPa} \cdot \mathrm{s}$ \\
& 2 & $\leq 5 \mathrm{mPa} \cdot \mathrm{s}$ & $\leq 5 \mathrm{mPa} \cdot \mathrm{s}$ & $\leq 5 \mathrm{mPa} \cdot \mathrm{s}$ & $\leq 5 \mathrm{mPa} \cdot \mathrm{s}$ & $\leq 5 \mathrm{mPa} \cdot \mathrm{s}$ \\
\hline
\end{tabular}

The gel can be completely broken to less than $5 \mathrm{mPa} \cdot \mathrm{s}$ with very low gel-breaker concentration (0.005\%). However, at the same condition, ZCY-10 gel cannot be broken thoroughly, even with very high gel-breaker concentration $(0.05 \%)$. At $140^{\circ} \mathrm{C}$, JDY-1 gel also showed very good gel-breaking property; moreover, at the same condition, ZCY-10 gel with very high gel-breaker concentration $(0.1 \%)$ can also be thoroughly broken for first few hours, but after 12 hours, the gel appeared again.

The reasons for this result can be explained. First of all, oxidized gel breakers, such as ammonium persulfate $\left.\left(\mathrm{NH}_{4}\right)_{2} \mathrm{~S}_{2} \mathrm{O}_{8}\right)$ and potassium persulfate $\left(\mathrm{K}_{2} \mathrm{~S}_{2} \mathrm{O}_{8}\right)$, were used to oxidize crosslinking bonds and polymer chains in order to break the cross-linked gels. As oxidized gel breakers can produce [O], the acetal bonds of vegetable gum and its derivatives were oxidized and degraded. Then, the oxidative degradation reaction of guar gum occurred under alkaline conditions. The active mechanism of the temperature stabilizer (such as sodium thiosulfate $\left(\mathrm{Na}_{2} \mathrm{~S}_{2} \mathrm{O}_{3}\right)$, triethanolamine $\left(\mathrm{C}_{6} \mathrm{H}_{15} \mathrm{NO}_{3}\right)$, and sulfite) was to improve the thermal stability of thickener by removing free oxygen in the liquid and reducing its catalytic effect on thermal degradation of polymer, in order to stabilize the performance of the fracturing fluid in high-temperature environment. Therefore, the addition of the temperature stabilizer will inevitably consume oxidized gel breaker, which will result in the incomplete gel breaking of the fracturing fluid. Moreover, the addition of a large amount of salt prevented the oxidation reaction between ammonium persulfate and acetal bond, which would also lead to incomplete gel breaking. 


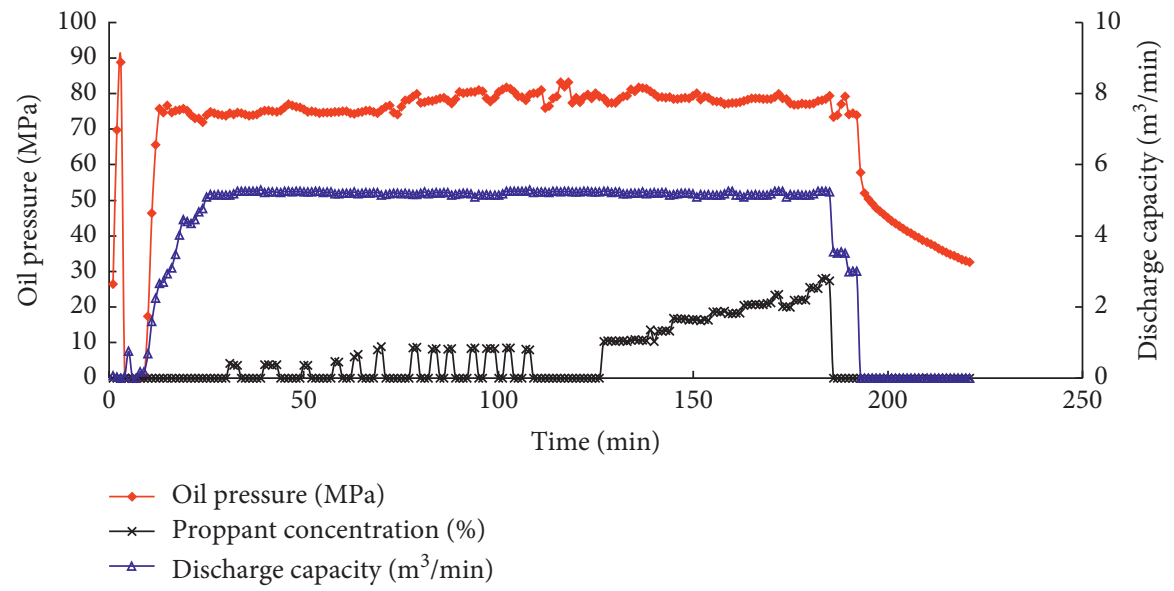

FIGURE 9: Fracturing construction curve of the NPXX well.

\section{Field Application}

The new weighted fracturing fluid was used in the fracturing project of an old well in Nanpu oilfield, Jidong, China. The reservoir has a vertical depth of $4823 \sim 4863 \mathrm{~m}$, thickness of $10.5 \mathrm{~m}$, and temperature of $168^{\circ} \mathrm{C}$. The NPXX well has used $3^{1 / 2}$ tubing size with RTTS packers. According to the data of adjacent wells, the closure stress gradient of this well was estimated to be $0.021 \mathrm{MPa} / \mathrm{m}$, and breakdown pressure was predicted to be $102 \mathrm{MPa}$ using the conventional density $\left(1.0 \mathrm{~g} / \mathrm{cm}^{3}\right)$ fracturing fluid system. Figure 9 demonstrates the fracturing construction curve of NPXX. The treatment was successfully constructed with the new weighted fracturing fluid system with a density of $1.36 \mathrm{~g} / \mathrm{cm}^{3}$. During the process, the construction pressure ranged from 75 to $83 \mathrm{MPa}$, the maximum injection rate was $5.2 \mathrm{~m}^{3} / \mathrm{min}$, and the total fluid and proppant volume were $830 \mathrm{~m}^{3}$ and $54 \mathrm{~m}^{3}$, respectively. The maximum sand concentration was $525 \mathrm{~kg} / \mathrm{m}^{3}$. After fracturing, a $5 \mathrm{~mm}$ nozzle was used for flowback, and the flowback rate was $85 \%$. Furthermore, daily oil production reached $10 \mathrm{t} / \mathrm{d}$, which was higher than adjacent wells. The success of this treatment implies the new ultralow guar gum concentration weighted fracturing fluid can completely meet the requirements under reservoir conditions. Moreover, it provides strong technical support for reservoir reconstruction in high-temperature deep wells in Jidong oilfield.

\section{Conclusion}

The following conclusions can be drawn:

(1) A polyboric acid cross-linker (JDY-1) was synthesized by optimizing the source of boric acid and the grade of sodium gluconate, compounding the crosslinking ligand (16 wt\% sodium gluconate 2 and $7 \mathrm{wt} \%$ ester ligand) and increasing the amount of boric acid to $25 \mathrm{wt} \%$.

(2) The composition of the new weighted fracturing fluid was confirmed: $0.45 \% \mathrm{HPG}+0.5 \%$ regulator $+0.15 \%$ $\mathrm{Na}_{2} \mathrm{CO}_{3}+0.3 \%$ cleanup additive $+0.5 \%$ antiswelling agent $+1 \% \quad \mathrm{KCl}+0.6 \% \quad$ JDY- $1+0.1 \%$ temperature stabilizer $+40 \%$ sodium nitrate B. This fluid system can withstand very high temperature up to $175^{\circ} \mathrm{C}$ with a density of $1.365 \mathrm{~g} / \mathrm{cm}^{3}$. After optimization, the guar gum concentration was effectively reduced in the new weighted fracturing fluid, and the difficulties during the pumping process in the high-temperature reservoir $\left(\geq 150^{\circ} \mathrm{C}\right)$ have been solved.

(3) The new weighted fracturing fluid has excellent gelbreaking performance. The gel can be broken thoroughly to less than $5 \mathrm{mPa} \cdot \mathrm{s}$ by using gel-breaker with very low concentration $(0.005 \%$ ammonium persulfate) at $120^{\circ} \mathrm{C}$ within 2 hours. This fluid system has solved many problems that the conventional weighted fracturing fluid would cause, such as high gel-breaker usage and difficulties in gel flowback.

\section{Data Availability}

The figures and field data used to support the findings of this study are included within the article and are available from the corresponding author upon request.

\section{Conflicts of Interest}

The authors declare no conflicts of interest.

\section{Authors' Contributions}

Yi Liu (liu0yi@163.com) contributed to the overall thinking of the manuscript, synthesis of JDY-1, optimization evaluation of the new weighted fracturing fluid, and preparation of the corresponding parts of the manuscript. Jing Liu (liujing188@petrochina.com.cn) contributed to the optimization of crosslinking ligands, synthesis and characterization of JDY-1, optimization of the weighting agent, and preparation of the corresponding parts of the manuscript. Yunzi Li (liyunzi2018@petrochina.com.cn) contributed to the literature research, current progress in weighted fracturing fluid research and its applications, performance evaluation of the weighted fracturing fluid, and the translation of the manuscript. Hui Yang (zcy_liuyi@ 
petrochina.com.cn) contributed to the performance evaluation of the weighted fracturing fluid and preparation of the corresponding parts of the manuscript. Fei Yan (zcy_yanfei@petrochina.com.cn) contributed to the optimization of boric acid and performance evaluation of the weighted fracturing fluid. Jiapeng Zheng (38076671@qq.com) contributed to the performance evaluation of the weighted fracturing fluid. Jun Wu (940568031@qq.com) contributed to the selection of the test wells and the field application of the weighted fracturing fluid. Jianyi Huang (huangjy188@ petrochina.com.cn) contributed to fluid preparation and fluid operation. Zuohao Wu (gsp_wzh@petrochina.com.cn) contributed to the rheology performance evaluation of the weighted fracturing fluid. Cheng Luo (jd_luocheng@petrochina.com.cn) and Junkai Lu (lujunkai@petrochina.com.cn) contributed to the fracturing engineering design of the NPXX well (using the new weighted fracturing fluid system).

\section{Acknowledgments}

This study was supported by the Major Projects of PetroChina (2016ZX050060060), Study on technical and economic feasibility of Frac-Stimulation development in small scale sand body (KT2018-12-01), and the Major Project of Jidong Oilfield (KT2017A03).

\section{References}

[1] B. Xia, G. Zhang, and C. Bo, "Effects of $\mathrm{NaCl}$ and $\mathrm{NaBr}$ on the performance of HPG fracturing fluid," Oil Field Chemical, vol. 30, no. 31, pp. 68-70, 2013.

[2] D. V Satya Gupta, "Evaluation of a high-density brine viscosifier for ultra-deep fracture stimulation," in Proceedings of the SPE Hydraulic Fracturing Technology Conference and Exhibition, pp. 1-7, Woodlands, TX, USA, January 2011.

[3] F. Huang, R. S. Gundewar, B. W. Loughridge, and D. L. Steed, "Feasibility of using produced water for cross-linked gel-based hydraulic fracturing," in Proceedings of the SPE Production Operations Symposium, Oklahoma City, Oklahoma, April 2005.

[4] X. Yuan, Y. Tang, J. Liu, Z. Yan, and Q. Wang, "Study on the reasons for the decrease of fracturing fluid flowback density in keshen gas reservoir drilling," Production Technology, vol. 40, no. 4, pp. 101-105, 2017.

[5] P. Zhao, Z. Tang, R. Ma, and Q. Chang, "Screening and field test of organic boron as cross-linker in fracturing fluid," Petrochemical Industry Application, vol. 36, no. 6, 2017.

[6] X. Dan, T. Liu, and J. Wei, Meng Wang the Study on a Delayed Crosslinking High Temperature Guar Gum Weighting Fracturing Fluid Journal of Southwest Petroleum University, Natural Science edition, Springer, Berlin, Germany, 2020.

[7] J. Xing, J. Guo, and J. Zhao etc, "Development and evaluation of a new ultra-high temperature fracturing fluid system," Drilling Fluid and Completion Fluid, vol. 26, no. 6, pp. 49-52, 2009.

[8] L. Zhao, "Study and application of a slow crosslinking high temperature and high density fracturing fluid," Journal of Petroleum and Natural Gas (Journal of Jianghan Petroleum University), vol. 35, no. 12, 2013.
[9] J. Xie, B. Xiao, and Y. Cheng, "Research and application of high temperature and high density fracturing fluid," Petrochemical Application, vol. 30, no. 12, pp. 43-45, 2011.

[10] H. Xiao, J. Guo, and C. He, "Study and application of fracturing fluids," Petroleum and Natural Gas Chemical Industry, vol. 42, no. 2, pp. 168-172, 2013. 